\title{
Effect of Submerging Solanum lycopersicum Roots in Salicylic Acid (SA) Solution for Different Durations on Nematode Infection and Expressions of SIPR5 Gene
}

\section{Refik BOZBUGA ${ }^{1}$}

${ }^{1}$ Biological Control Research Institute, 01321, Adana / Turkey

\section{Article History}

Received 01 November 2020

Accepted 25 November 2020

First Online 30 November 2020

\section{Corresponding Author}

E-mail: refikbozbuga@gmail.com

\section{Keywords}

Gene expression

Meloidogyne incognita

PR5

Salicylic acid

Solanum lycopersicum

\begin{abstract}
Salicylic acid (SA) stimulates the mechanism of the plant defence and involves in a role in plant pathogen interactions. Plant parasitic nematodes are important biotic stresses causing negative effect on plant growth and development. Treatment of plant roots with SA may increase the plant defence mechanisms against biotic stresses. However, the treated effect of SA on plant defence mechanisms against a root-knot nematode, Meloidogyne incognita, has not been fully understood in terms of plant pathogen interactions. Therefore, this study was aimed to determine the most effective SA exposure time on increasing the plant defence and decreasing the nematode parasitism in Solanum lycopersicum. In addition, effects of SA treatment on the expression Pathogenesis Related Gene 5 (PR5) was evaluated. For this aim, tomato seedlings were exposed within $1000 \mu \mathrm{M}$ SA concentration with distinctive time durations. The expression of PR5 gene was accomplished using RT-PCR at 1, 3, 7, 14, 21 days post infection (dpi) for each sample. Root galling index, nematode number and reproduction rate were evaluated. Results revealed that nematode reproduction rate was decreased at in longer durations after SA treatment on roots. The highest nematode reproduction rate was determined in nematode+water (non-SA treatment) application compare to SA treatments. The highest increased level of expression of SIPR5 gene was determined in early ( $1 \mathrm{dpi}) \mathrm{SA}$ treatment + nematode infection. To conclude, SA treatment may increase the plant defence mechanisms and PR5 gene may involve in nematode-plant parasitism.
\end{abstract}

\section{Introduction}

Root-knot nematodes (Meloidogyne spp.) are placed on the top among plant parasitic nematodes (Jones et al., 2013) that they destroy crops as giving damage billions of euros on each year. A most polyphagous nematode genus, Meloidogyne, has around 100 species. Among them, $M$. incognita, $M$. hapla, $M$. arenaria and $M$. javanica are termed as major species of Meloidogyne genus and those species are found many countries in the world (Elling, 2013). Meloidogyne species are obligate parasite infect most plant species and cause galls in roots including legumes (Bozbuga et al., 2015a; Bozbuga, 2020a). Female nematode deposits eggs within egg mass composed of gelatinous matrix produced from rectal glands (Elling, 2013). Following the embryogenesis of first stage of juveniles (J1s) within egg, hatching occurs subsequent the development of second stage juveniles (J2s). To be an infected stage of Meloidogyne species, J2s penetrate plant roots just behind the root tip and migrate intercellularly within cells through the cortex. When they reach to vascular cylinder J2s become sedentary and induces changes in plant tissue. Following the 
establishment of the nematode, the modification of cell wall molecular architecture occurs in feeding site of root-knot nematodes (RKN) (Bozbuga et al., 2018). Alteration of cell wall polysaccharides and cell wall thickening are seen in nematode feeding site that these modifications may related to suck up nutrients from plants (Bozbuga, 2017). Nematode induced feeding cells become multinucleated and large called "Giant cells" (Bird and Kaloshian, 2003). Giant cell and nematode sizes increase, and root swelling occurs within 3-4 days (Bartlem et al., 2014). The changes of lateral expansion of giant cells lead to differentiation of sieve elements, xylem vessels and phloem cells occurs (Bozbuga, 2017). During the feeding, J2s undergo several moults and finally become adults and starts produce eggs within the egg masses (Moller et al., 1998).

Some tomato plants have resistance gene (Mi gene) against root-knot nematode (Bozbuga et al., 2020). Plant cell wall plays a crucial role against pathogens with several physical barriers, cellulose, hemicellulose, lignin, proteins, and chemical substances (Heredia et al., 1995). Nematode modifies cell wall molecular architecture for feeding to continue its life (Bozbuga et al., 2018). Pathogens can be recognised by cell surface localised pattern recognition receptors by greatly conserved pathogen associated molecular patterns that pathogen triggered immunity involves in inhibiting the pathogen growth and modify pathogen molecules (Jones and Dangl, 2006). Pathogen Related (PR) proteins are stimulated to response to pathogens (van Loon et al., 1994).

As a significant hormone, SA participates the plant defence regulations, plant growth and plant development (Yan et al., 2014). As a transcription co-activator, NPR1 is a fundamental regulator of the plant defence response (Shi et al., 2010). NPR3, NPR4 is involved in SA regulation, and NPR3 and NPR4 bind SA to regulate NPR1 steadiness (Yan et al., 2014; Zhao et al., 2015) and defence responses (Moreau et al., 2012). SA is important component involves in Mi mediated defence response against Meloidogyne in tomato plant (Branch et al., 2004) and SA methyltransferase gene involves in Heterodera glycinesis in soybean (Lin et al., 2013). The changes of plant gene expressions are linked nematode parasitism. Gene expression is achieved a Realtime Polymerase Chain Reaction (RT-PCR) technology. Quantitative reverse transcriptase PCR (qRT-PCR) is used for quantifying mRNA transcription levels (Ginzinger, 2002).

In this study, a root-knot nematode, $M$. incognita was selected due to be a most damaging RKN species in the world. Effect of salicylic acid (SA) on tomato plants to $M$. incognita and expressions of Pathogenesis related 5 (PR5) gene following the treatment of SA need to be fully understood. Hence, this study was aimed to determine the effect of different exposure time of SA on RKN, M. incognita reproduction and plant parameters and determining the PR5 gene expressions activated by nematode infection using qRT-PCR.

\section{Material and Methods}

The susceptible tomato (Solanum lycopersicum L.) seedlings were grown in pots for inoculation of $M$. incognita used for nematode reproduction to use in this study. Meloidogyne incognita pure population was grown to gain sufficient number for nematode inoculation. Nematode induced tomato galled roots were cut into $1 \mathrm{~cm}$ length and placed on modified Baermann funnel for extraction in the nematology lab. Second-stage juveniles (J2s) of the nematode were extracted using modified Baermann funnel method and counted under the microscope to optimise under the microscope counting the numbers for setting up the experiment. Tomato seedlings were placed on the $1 \mathrm{~kg}$ volume-pots filled with sterilised growing mix for the experiment. Pots were placed on the $25 \pm 2^{\circ} \mathrm{C}$ in the greenhouses. Soil mix was consisted of $80 \%$ stream sand $+20 \%$ soil at $126^{\circ} \mathrm{C}$ in autoclave to eradicate pathogens, pests and seeds. Soil mix sterilisation is important for set up experiment. Sterilised soil mix were filled within pots and tomato seedling were gently placed after SA treatment; then, 2000second stage juveniles (j2s) of $M$. incognita/per plant (2 J2s/gram soil) were inoculated (Bozbuga et al., 2015b). The experiment was set up according to randomised block design with 5 repetitions.

The concentration of SA was achieved as $1000 \mu \mathrm{M}$. SA concentration was selected based on the previous pre-experimental studies. The roots of 25-day-old tomato seedlings were placed in SA concentration $(1000 \mu \mathrm{M})$ at 1 minute, 5 minutes, 30 minutes, 60 minutes, 120 minutes and 240 minute exposure times. Control treatments nematode+water and non-nematode+water treatments were also set up as controls. SA treated tomato plants were positioned in the $1 \mathrm{~kg}$ of pots and $2000 \mathrm{~J} 2 \mathrm{~s}$ were transferred within the root region in the pot with 5 replications for each treatment. Following the treatment, no watering was applied for seven days. All treatments including controls were set up as five replications. Plants were placed in greenhouses for two months at the $25 \pm 2^{\circ} \mathrm{C}$ with 16 daylight with 8 hours dark conditions. Plant parameters were evaluated after two months following the nematode infection and SA treatment.

Nematodes parameters were assessed to determine the nematode- plant parasitism relationship and nematode reproduction rate is an important indicator for nematode population. Nematode reproduction rate was calculated as final population number dividing the initial inoculation number.

Root gall index were achieved using the 0-5 egg sacs and gall index as $0=$ no galls and no egg sacs, $1=1-2$ egg sacs and galls; $2=3-10$ egg sacs and galls; $3=11-30$ egg sacs and galls; $4=31-100$ egg 
sacs and galls and $5=>100$ egg sacs and galls in each root system (Hartman and Sasser, 1985).

Determining the PR5 expression in tomato leaves were collected following $M$. incognita infection at 1, 3, 7, 14- and 21-days post infection (dpi) was analysed by using qRT-PCR. Leaves of five tomato plants from each replicate were taken and placed in liquid nitrogen. The GeneJET plant RNA purification mini kit (Thermo Scientific, Lithuania) was used for isolation of RNA from plant tissues and the company protocols were followed for RNA purification. Plant RNA lysis Solution was pipetted $(500 \mu \mathrm{L})$ and into $1.5 \mathrm{~mL}$ micro centrifuge tube. Plant tissue was weighed at $100 \mathrm{mg}$ from frozen tissue and grinding the plant tissues using mortar and pestle into the liquid nitrogen. Incubation was performed for $3 \mathrm{~min}$ at $56^{\circ} \mathrm{C}$ and centrifuged at $14000 \mathrm{rpm}$ for 5 minutes. Supernatant was collected and transferred to the clean micro centrifuge tube and added $250 \mu \mathrm{L} 96 \%$ ethanol. Following the transferring of mix to the purification column they were centrifuged. The flow-through solution was discarded and $700 \mu \mathrm{L}$ of wash buffer 1 were added to the purification column and centrifuged. Flow-through protocol was achieved and $500 \mu \mathrm{L}$ wash buffer 2 was added to purification column and centrifuged then, flow-through solution was discarded. Re-spinning of the column at 14000 rpm for a $60 \mathrm{sec}$ was achieved, and purification column was transferred to a RNase-free $1.5 \mathrm{~mL}$ collection tube, and nuclease-free water was added to elute RNA and centrifuged. Purified RNA was measured in Nanodrop and diluted at $100 \mathrm{ng}$. Then conversion of cDNA synthesis of RNA was performed by iScript ${ }^{T M}$ CDNA Sythesis Kit (Bio-Rad) to use solution for two step reverse transcription quantitative PCR (RT-qPCR). Following the cDNA synthesis, SSoAdvanced ${ }^{\mathrm{TM}}$ Universal SYBR Green Supermix (Bio-Rad, USA) were used. The reaction set up was achieved using the SSoAdvancedTM Universal SYBR Green Supermix (Bio-Rad, USA), forward and reverse primers, cDNA template and Nuclease free water. Repeated reverse transcription-polymerase chain reaction (RT-PCR) assessment of gene expression was achieved. Nematode and non-nematode infected samples were studied to reveal gene expression during the nematode infection. Solanum lycopersicum pathogen related gene 5 (SIPR5) was taken determine the gene expression. SIPR5 Forward: 5'AATTGCAATTTTAATGGTGC-3', Reverse: 5'TAGCAGACCGTTTAAGATGC-3' (Kavroulakis et al., 2006) was used as pathogenesis related gene expressions. The primers of housekeeping gene, SIActin gene, was selected as Forward: 5'ATGTATGTTGCCATCCAGGCT-3', Reverse: 5'TGTGGCTGACACGATCTCCA-3' and it was performed to normalize the expression of gene (Chinnapandi et al., 2017). Cycling conditions were polymerase activation and DNA denaturation 60 sec in $95^{\circ} \mathrm{C}$, denaturation at $95^{\circ} \mathrm{C}$ for $15 \mathrm{sec}$, amplification annealing/extension and plate read at $55^{\circ} \mathrm{C}$ for $60 \mathrm{sec}$ with 45 cycles. To check the specificity of the PCR product, the melting curves were analysed for each data point. Repetition was performed for three samples for each treatment. The data of cycle number at which defined florescent threshold was crossed (ct values). The change of relative gene expression was calculated using the $2^{-} \triangle \Delta \mathrm{CT}$ method and control uninfected values were subtracted from infected values.

Nematode and plant parameters were designed a complete randomised block design and one way of analysis of variance on pot data of five repetitions to compare results. The data of evaluation parameters were analysed using Duncan's Multiple Range Test at $(P=0.05)$ in SPSS to observe the significant differences among the values.

\section{Result and Discussion}

Gene expression was performed to understand the effect of SA exposure time on pathogen related gene expressions on tomato leaves. Tomato leaves was selected to understand the systemic response of plants against nematode and effect the SA treatment after infection of nematode at 1, 3, 7, 14and 21-days post infection (dpi). For this aim, quantitative reverse transcription-polymerase chain reaction (qRT-PCR) was achieved to determine the gene expression. Following the RNA extraction and cDNA synthesis from tomato leaves in nematode infected, control (non-nematode), 1000 uM SA treated + nematode infected were evaluated using SIPR5 genes. The expression of PR5 reached at highest at 1 dpi day in SA treatment+nematode infection (Figure 1).

PCR analysis following the infection of $M$. incognita on SA treated $\mathrm{SA}+$ nematode and nematode treatments in tomato plants at 1 days post infection (dpi), $3 \mathrm{dpi}, 7 \mathrm{dpi}, 14 \mathrm{dpi}, 21 \mathrm{dpi}$. A reference gene (actin) was used to normalise mRNA levels of target genes. Fold change of relative gene expression was calculated with 3 biological replicates using $2-\Delta \Delta C T$ method. Control (uninfected) mean of $\Delta \mathrm{CT}$ of three replication value was subtracted from the infected sample mean. Therefore, the value of control group was not showed in the figure. $Y$ axis represents the relative gene expression and $X$ axis indicates $M$. incognita infection at different dpis. Mi, Meloidogyne incognita, Error bars indicate the standard error of the means of three replicates.

The relative gene expression of SIPR5 decreased at 3 and $7 \mathrm{dpi}$ in the treatment of $\mathrm{SA}+$ nematode. However, gene expressions were not increased in early dpis but gradually increased until $14 \mathrm{dpi}$ in nematode infected (without SA treatment) samples (Figure 1). This result may reveal that SA involves in gene expression and possibly related to plant resistance against nematode. In general, the relative expressions of PR5 gene was expressed in high level in 


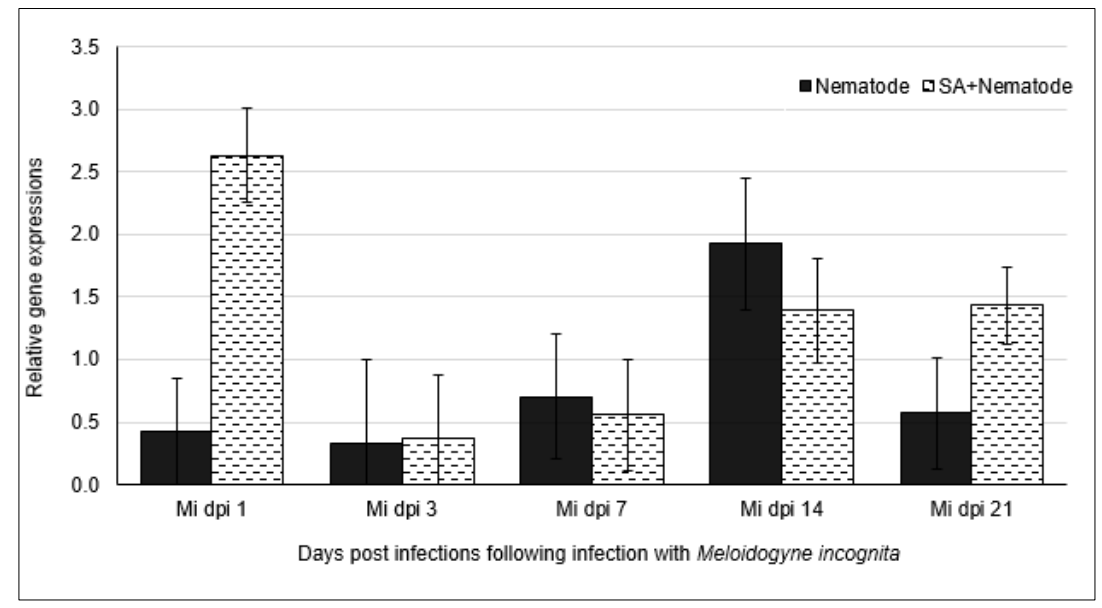

Figure 1. Expression of Pathogenesis-related gene 5 (PR5) (Nematode induced expression of Pathogenesis-related gene 5 (PR5) using RT-PCR analysis following the infection of $M$. incognita on Salicylic acid (SA) treated SA+Nematode and nematode treatments in tomato plants at $1,3,7,14$, and 21 dpis (days post infection). A reference gene (actin) was used to normalise mRNA levels of target genes. Fold change of relative gene expression was calculated with 3 biological replicates using $2^{-\triangle} \Delta \mathrm{CT}$ method. Control (uninfected) mean of $\Delta \mathrm{CT}$ of three replication value was subtracted from the infected sample mean. Therefore, the value of control group was not showed in in the figure. $\mathrm{Y}$ axis represents the relative gene expression and $\mathrm{X}$ axis indicates $M$. incognita infection at different dpis. Mi, Meloidogyne incognita, Error bars indicate the standard error of the means of three replicates).

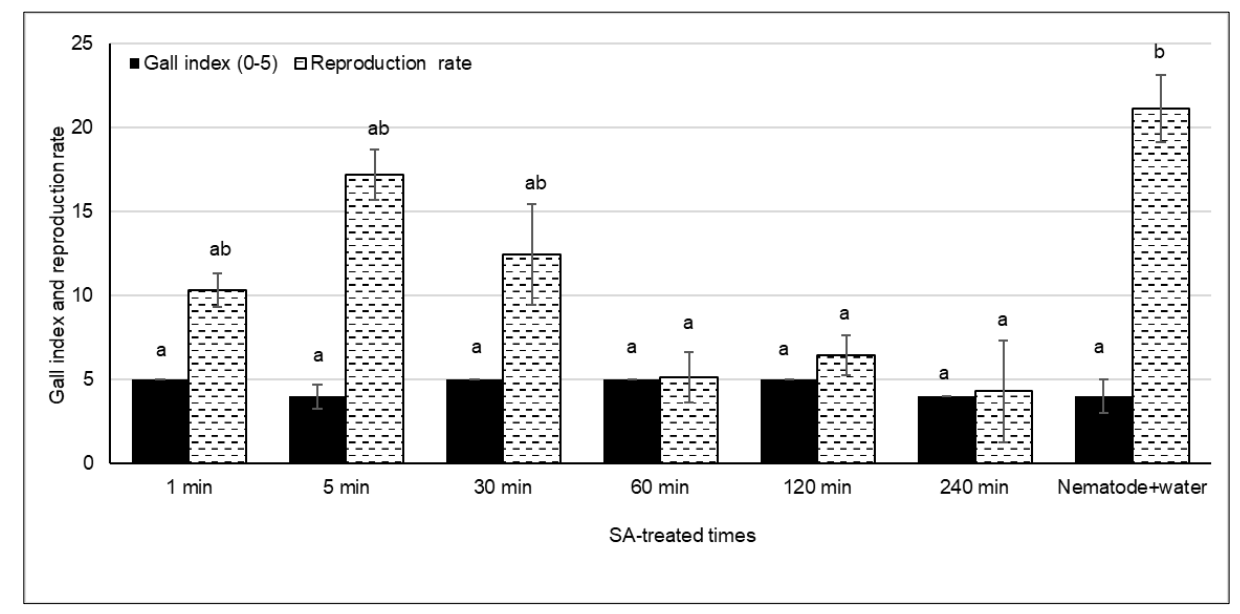

Figure 2. Effects of Salicylic Acid (SA) exposure times on nematode reproduction rate and gall index following the infection by $M$. incognita ( $Y$ axis indicates value of $0-5$ gall index and nematode reproduction rate. $X$ axis represents control and $S A$ exposure time following the application of different time durations (1 minutes, 5 minutes, 30 minutes, 60 minutes, 120 minutes, 240 minutes. Gall index and reproduction rate were evaluated individually during the statistical evaluation. Error bars represents the standard error of the means of five replicates and letters characterise the statistical differences among different doses. Min, minutes).

$\mathrm{SA}+$ nematode treatment compare to non-SA treatment. It means that nematode may suppress the plant defence mechanism in early parasitism, since gene expressions increases following the SA treatment in early nematode parasitism.

Root gall index and nematode reproduction rate important components to determine the SA effect on nematode development and plant resistance against nematode. Several SA exposures time (1 $\mathrm{min}, 5 \mathrm{~min}, 30 \mathrm{~min}, 60 \mathrm{~min}, 120 \mathrm{~min}$ and $240 \mathrm{~min}$ ) were performed to determine the effect of SA exposure time on nematode reproduction and gall index in plant root. Root gall index was measured using the 0-5 gall index following the SA treatment doses. No significant differences found among the applications in gall index parameter in root system in $1 \mathrm{~min}, 5 \mathrm{~min}, 30 \mathrm{~min}, 60 \mathrm{~min}, 120 \mathrm{~min}$ and 240 min applications. Nematode may enter plant roots then cause gall, however SA teratment may negatively affect the nematode development and reproduction. Therefore, gall index may not be fully show plant resistance. Nematode reproduction rate is an important parameter to show nematode feeding on root and multiplying the population. Highest nematode reproduction rate was determined in the application of nematode+ water treatment (Figure 2). In general, nematode reproduction rate was high at $1 \mathrm{~min}, 5 \mathrm{~min}, 30 \mathrm{~min}$ and non-SA (control) treatments (Figure 2).

This means that treatment with SA on plant roots at $60 \mathrm{~min}, 120 \mathrm{~min}$ and $240 \mathrm{~min}$ plays negative effect on nematode reproduction rate. Salicylic acid involves in plant defence mechanisms (Yan et al., 2014) that may have been produced during the pathogen attack. Similarly treating with SA on plants lead to inhibitory effect of SA on $M$. javanica 
reproduction in tomato plants (Moslemi et al., 2016). In this study, nematode number was decreased in SA treated plants that possibly related that SA activated the pathogen related genes. Increased level of PR5 genes in early infection days (Figure 1) may closely related to the plant defence mechanism.

During the pathogen attack, plant response with multiple layers of defences and triggers resistance to pathogens and SA involves in defence response (Vlot et al., 2009). During the nematode infection, the thickness of nematode induced host cell walls are around 5 times thicker than neighbouring cell walls (Bozbuga, 2017). More than seven hundred of genes are down regulated in $M$. incognita feeding site and few genes are downregulated (Fuller et al., 2007). Similarly, the number of upregulated genes was three times higher than the number of downregulated genes ( $\mathrm{Li}$ et al., 2009). The SA receptor NPR3 is a negative regulator of the transcriptional defence response during early flower development in Arabidopsis (Shi et al., 2013). The expression of $P R$ genes changes important signalling molecules for the development of plant immune response (van Loon et al., 2006). Upregulation of $P R 1$ gene is seen in early and late days nematode post infection in tomato plants (Bozbuga, 2020b). The expression of some $P R$ genes in tomato tissues on SA treated susceptible plants to nematodes is increased and may closely related defence mechanism against nematode (Lavrova et al., 2017).

\section{Conclusion}

The application of SA reduced the nematode reproduction rate in tomato plants and expression of pathogen related gene may closely related to $S A$ for involving plant defences.

\section{References}

Bartlem, D.G., Jones, M.G.K., \& Hammes, U.Z. (2014). Vascularization and nutrient delivery at root-knot nematode feeding sites in host roots. Journal of Experimental Botany, 65:1789-1798.

Bird, D.M., \& Kaloshian, I. (2003). Are roots special? Nematodes have their say. Physiological and Molecular Plant Pathology, 62:115-123.

Bozbuga, R., Dasgan, H.Y., Akhoundnejad, Y., Imren, M., Toktay, H., \& Kasapoglu, E.B. (2015a). Identification of common bean ( $P$. vulgaris) genotypes having resistance against root knot nematode Meloidogyne incognita. Legume Research, 38:669-674.

Bozbuga, R., Imren, M., Kasapoğlu, E.B., Toktay, H. \& Elekcioğlu, I.H. (2015b). Determining the optimal Meloidogyne incognita inoculum level, inoculation time, pathogenicity and gall development on tomato roots for resistance experiments in breeding programs. Vegetos, 28:70-75.

Bozbuga, R. (2017). Characterisation of cell walls at the feeding site of Meloidogyne incognita, PhD thesis, University of Leeds, Leeds.
Bozbuga, R., Lilley, J.L., Knox, J.P. \& Urwin, P.E. (2018). Host-specific signatures of the cell wall changes induced by the plant parasitic nematode, Meloidogyne incognita. Scientific Reports, 8:17302.

Bozbuga, R., Dasgan, H.Y., Akhoundnejad, Y., Imren, M., Günay, O., \& Toktay, H. (2020). Effect of Mi gene and nematode resistance on tomato genotypes using molecular and screening assay. Cytology and Genetics, 54:154-164.

Bozbuga, R. (2020a). Expressions of pathogenesis related 1 (PR1) gene in Solanum lycopersicum and Influence of salicylic acid exposures on hostMeloidogyne incognita interactions. Doklady Biochemistry Biophysics, 494:266-269.

Bozbuga, R. (2020b). Genetics, molecular interactions and resistance response of common bean (Phaseolus vulgaris L.) genotypes to root knot nematodes (Meloidogyne spp.). Cutting-edge Research in Agricultural Sciences, 3:78-83.

Branch, C., Hwang, C.F., Navarre, D.A., \& Williamson, V.M. (2004). Salicylic acid is part of the Mi-1-mediated defense responses to root-knot nematode in tomato. Mol Plant- Microbe Interact, 17:351-356.

Chinnapandi, B., Bucki, P., \& Braun Miyara, S. (2017). SIWRKY45, nematode-responsive tomato WRKY gene, enhances susceptibility to the root knot nematode; $M$. javanica infection. Plant Signaling \& Behavior, 12: e1356530.

Elling, A.A. (2013). Major emerging problems with minor Meloidogyne species. Phytopathology, 103:10921102.

Fuller, V.L., Lilley, C.J., Atkinson, H.J., \& Urwin, P.E. (2007). Differential gene expression in Arabidopsis following infection by plant- parasitic nematodes Meloidogyne incognita and Heterodera schachtii. Molecular Plant Pathology, 8:595-609.

Ginzinger, D.G. (2002) Gene quantification using realtime quantitative PCR: An emerging technology hits the mainstream. Experimental Hematology, 30:503512.

Hartman, K.M., \& Sasser, J.N. (1985). Identification of Meloidogyne species on the basis of different host test and perineal pattern morphology. In: Barker, K.R., Carter, C.C., Sasser, J.N., (eds) An Advanced treatise on Meloidogyne, North Carolina State University Graphics, Raleigh, 2:69-77.

Heredia, A., Jimenez, A., \& Guillen, R. (1995). Composition of plant-cell walls. Zeitschrift Fur Lebensmittel-Untersuchung Und-Forschung, 200:2431.

Jones, J.D.G., \& Dangl, J.L. (2006). The plant immune system. Nature, 444: 323-329.

Jones, J.T., Haegeman, A., Danchin, E. G. J., Gaur, H. S., Helder, J., Jones, M. G. K., Kikuchi, T., ManzanillaLopez, R., Palomares-Rius, J. E., Wesemael, W. M. L., \& Perry, R. N. (2013). Top 10 plant-parasitic nematodes in molecular plant pathology. Molecular Plant Pathology, 14:946-961.

Kavroulakis, N., Papadopoulou, K.K., Ntougias, S., Zervakis, G.I., \& Ehaliotis, C. (2006). Cytological and other aspects of pathogenesis- related gene expression in tomato plants grown on a suppressive compost. Annals of Botany 98:555-564.

Lavrova, V.V., Zinovieva, S.V., Udalova, Z.V., \& Matveeva, E.M. (2017). Expression of PR genes in tomato tissues infected by nematode Meloidogyne incognita (Kofoid et White, 1919) Chitwood, 1949. Doklady Biochemistry and Biophysics, 476:306-309. 
Li, Y., Fester, T., \& Taylor, C.G. (2009) Transcriptomic Analysis of Nematode Infestation. In: Berg, R.H., Taylor, C.G. (eds) Cell Biology of Plant Nematode Parasitism, Plant Cell Monographs, 15, Springer, Berlin, Heidelberg.

Lin, J., Mazarei, M., Zhao, N., Zhu, N.J., Zhuang, X., Liu, W., Pan- talone, V.R., Arelli, P.R., \& Stewart Jr, C.N. (2013). Overexpression of a soybean salicylic acid methyltransferase gene confers resistance to soybean cyst nematode. Plant Biotech Journal, 11:1135-

Moller, S.G., Urwin, P.E., Atkinson, H.J., \& Mcpherson, M.J. (1998). Nematode-induced expression of atao1, a gene encoding an extracellular diamine oxidase associated with developing vascular tissue. Physiological and Molecular Plant Pathology, 53:7379.

Moreau, M., Tian, M., \& Klessig, D. (2012). Salicylic acid binds NPR3 and NPR4 to regulate NPR1-dependent defense responses. Cell Research, 22:1631-1633.

Moslemi, F., Fatemy, S., \& Bernard, F. (2016). Inhibitory effects of salicylic acid on Meloidogyne javanica reproduction in tomato plants. Spanish Journal of Agricultural Research, 14: e1001.

Shi, Z., Maximova, S.N., Liu, Y., Verica, J., \& Guiltinan, M.J. (2010). Functional analysis of the Theobroma cacao NPR1 gene in Arabidopsis. BMC Plant Biology, 10: 248

Shi, Z., Maximova, S., Liu, Y., Verica, J., \& Guiltinan, M.J (2013). The salicylic acid receptor NPR3 is a negative regulator of the transcriptional defense response during early flower development in Arabidopsis. Molecular Plant, 6:802-816.

van Loon, L.C., Pierpoint, W.S., Boller, T., \& Conejero, V. (1994). Recommendations for Naming Plant Pathogenesis-Related Proteins. Plant Molecular Biology Reporter, 12:245-264.

van Loon, L.C., Rep, M., \& Pieterse, C.M.J. (2006). Significance of inducible defense-related proteins in infected plants. Annual Review of Phytopathology, 44:135-162.

Vlot, A.C, Dempsey, D.A., \& Klessig, D.F. (2009). Salicylic acid, a multifaceted hormone to combat disease. Annual Review Phytopathology, 47:177-206.

Yan, S., \& Dong, X. (2014). Perception of the plant immune signal salicylic acid. Current Opinion in Plant Biology, 20:64-68.

Zhao, X., Wang, J., Yuan, J., Wang, X., Zhao, Q., Kong, P., \& Zhang, X. (2015). Nitric oxide-associated protein1 (AtNOA1) is essential for salicylic acidinduced root waving in Arabidopsis thaliana. New Phytology, 1:1-13. 